\title{
ARTIGOS
}

\section{"MINUTEROS": APROXIMAÇÃO DE PESSOAS TECNOLOGIA OBSOLETA AO SERVIÇO DA COMUNICAÇÃO}

\author{
Gustavo Adolfo Gomez Marino (UNESP); Julie Andrea Salcedo Rincón \\ (UFRJ); Olímpio José Pinheiro, Dr. (UNESP); Paula da Cruz Landim, Dra.
} (UNESP)

\section{RESUMO}

As combinações entre as necessidades dos entornos sociais, governamentais e empresariais geram novos modelos de desenvolvimento que fazem links entre situações tradicionais e atuais, dando como resultados novos cenários que oferecem interações peer-to-peer para gerar um mix de soluções nas quais o benefício é mutuo. "Minuteros" apresenta a análise de um modelo de serviço de comunicação que além de gerar renda e suscitar aproximações entre usuários, aproveita tecnologia em desuso com ciclos de vida adicionais como caminho para a sustentabilidade..

\section{ABSTRACT}

The combinations between the needs of the corporate, government and corporate environments generate new development models that make links between traditional and current situations, giving as results new scenarios that offer peer-to-peer interactions to generate a mix of solutions in which the benefit is mutual. "Minuteros" presents the analysis of a communication service model that besides generating income and raise similarities between users, leverages technology into disuse with additional life cycles as a path to sustainability. 


\section{INTRODUÇÃO}

Muitos dos problemas ambientais da atualidade são o resultado de decisões tomadas no campo do design. $80 \%$ do impacto ambiental dos produtos, serviços e infraestrutura ao nosso redor são determinados pelo designer. Decisões sob materiais, processos de transformação, consumo energético, estratégias de consumo massificado, e o que acontece com eles quando perdem a utilidade, são tomadas em equipes onde o designer esta presente.

A partir disso, têm surgido diferentes vertentes do design para garantir a sustentabilidade, promovendo o desenvolvimento de novas formas de consumo, que visam não só à questão física, criando sistemas inovadores de serviços que promovem práticas ambientais. Com isso, surgem alternativas desde o design social, design de serviços, desmaterialização de produto e/ou ciclos de vida adicionais para produtos em desuso, que procuram introduzir-se no cotidiano de uma sociedade movimentada numa economia consumista.

Diante dessa situação, aparecem pessoas com soluções inovadoras, que ao invés de esperar respostas dos governos, instituições e organizações, lideram os câmbios desde seus próprios contextos, criando alternativas para seus problemas cotidianos.

Este trabalho apresenta um estudo de caso promissório de inovação Social desenvolvido no contexto Colombiano. Procura-se entender por quê uma iniciativa de serviço que partiu da comunidade, consegue instituir-se na cultura de todo um país, tanto em ambientes urbanos como rurais. Para analisar o caso parte-se dos conceitos de design para a sustentabilidade, design de serviços e inovação social.

Na Colômbia uma prática muito popular de economia informal é a venda do serviço de ligações desde o celular, comumente chamado de venda de minutos ou "minuteros", com essa prática, consegue-se o reaproveitamento de tecnologia em desuso, garantindo a rentabilidade por um serviço e suscitando conexões singulares entre pessoas que normalmente não convergiriam em outras circunstancias.

\section{DESENVOLVIMENTO}

\section{O design para a sustentabilidade}

A transição para a sustentabilidade exige uma profunda mudança na cultura industrial. Em particular, será necessária a reorientação de ideias de negócio, para evoluir do modelo de negócio tradicional que é orientado para o produto, para uma nova concepção de "produto-serviço" (MANZINI, 1999).

Nos séculos XIX e XX, o desenvolvimento pós-industrial, o consumismo desenfreado e as rápidas mudanças frente à moda e o estilo, conseguiram introduzir a "cultura do descartável" dentro do cotidiano da sociedade (SPARKE, 2010) . $\mathrm{Na}$ atualidade, o mundo industrializado centra seus esforços para tratar de encontrar novas formas de produção a fim de não afetar o equilíbrio natural, mas a realidade aponta a que nosso sistema econômico não tem como responder a essas necessidades.

O fato de não projetar produtos, bens e serviços com melhor desempenho ambiental não é por falta de ferramentas. Jhonatham Chapman explica como nos últimos 40 anos têm surgido diversas estratégias focalizadas no design sustentável - algumas delas focadas no ciclo de vida dos produtos - utilizando metodologias como o design for X (DFX) com técnicas especializadas segundo o tipo de projeto (Design para a Manufatura (DFM), Design para o desmontagem (DFD), Design para o Reciclagem (DFR), Design para o Meio ambiente (DFE), entre outros). Por outro lado, expõe a criação de estratégias mais populares que incluem alternativas energéticas, abastecimento de materiais e processos locais procurando evitar a deslocação, gestão na cadeia de subministros, zero emissões, produtos compostáveis, produtos sem embalagens, por citar alguns deles. (CHAPMAN, 2009 P6)

Por outro lado, Chapman expor igualmente a extensa variedade de materiais de baixo impacto com que os designers atuais contam, desde polímeros reciclados como polietileno, polipropileno ou aqueles plásticos biodegradáveis feitos a partir do amido vegetal; de metais como o aço, alumínio ou latão ate chegar a tecidos feitos em base de fibra natural. Estas matérias primas conseguem ser aplicadas no design, na arquitetura e em outras áreas que geram estratégias sedutoras de aproveitamento, de tal forma que se faça melhor uso dos recursos que já foram extraídos e transformados, e, que podem recircular dentro da cadeia de produção de bens e serviços para a satisfação das necessidades humanas.

A literatura neste aspecto é ampla, Victor Papanek em 1977 com seu livro design for the real world da diretrizes para considerar a sustentabilidade no processo de projeto dos produtos e junto a pensadores chaves do design como Nigel Whiteley, Fritz Schumacher e Ezio Manzini entre outros, começa surgir soluções eficientes e reesposáveis aplicáveis no desenvolvimento de produtos e serviços mais eficientes não só com o meio ambiente, mas social e economicamente. 


\section{Desmaterialização do Produto}

A necessidade de desmaterializar os produtos e a mudança do conceito de "bem-estar" se faz cada dia mais notável conforme observamos os efeitos decorrentes da atividade produtiva sobre o meio ambiente. Como foi mencionado por Karl Marx nas suas cartas a Ricardo (Marx, apud, Papanek (2007), Pág. 208) é eminente a desmaterialização dos produtos (onde se busca fugir da "objetificação das necessidades") e mudar as concepção de bem-estar através da proposição de novas soluções que combinem a demanda e a oferta de produtos e serviços. Essas soluções devem ser caracterizadas por diferentes graus de inovação no plano técnico e/ou no plano sociocultural (Manizi e Vezzoli, 2002 Pág 64).

Ao respeito, Ezio Manzini destaca o momento de eliminação do produto e como podem se levar em conta alternativas para seu destino final desde a sua concepção. Pode-se recuperar a funcionalidade do produto ou de qualquer componente?, Pode-se valorizar as condições do material empregado ou o conteúdo energético?, ou finalmente, pode-se optar por não recuperar nada do produto. $\mathrm{O}$ autor convida a considerar ciclos de vida adicionais antes de sua eliminação, referindo à função que o mesmo produto assume. Exemplifica com as embalagens, as estruturas físicas que aparecem durante o uso dos produtos, que também vão a determinar os impactos ambientais dele. (Idem, Op.cit, P96)

\section{O Design para a inovação social}

Muitos elementos do mundo sustentável já existem, alguns elementos são soluções tecnológicas, outros serão encontrados no mundo natural. A maioria das soluções estão compostas de práticas sociais - algumas muito antigas que evoluíram em outras sociedades e outros tempos. (THACKARA, 2008 P31)

Para muitas pessoas falar de inovação supõe uma adição de tecnologia necessariamente. Na realidade os dilemas de inovação aparecem ao abordar a questão: onde queremos estar?, que dependendo do contexto, muitas vezes a tecnologia não é a melhor solução . A Comissão Económica para América Latina e o Caribe (CEPAL) define a inovação social como :

Novas formas de fazer coisas, novas formas de gestão com respeito ao estado da arte na região, que permitam melhores resultados que os modelos tradicionais, que sejam eficientes economicamente e além disso, promovam e fortaleçam a participação da própria comunidade e os beneficiários, os convertendo em verdadeiros atores de seu próprio desenvolvimento e portanto fortalecendo a consciência cidadã, e com isso a democracia de nossa região.

O design para inovação social abrange o planejamento de produtos, serviços, processos e políticas que conseguem atender uma necessidade social de forma mais eficaz da solução atual. ICSID (apud Langenbach, 2008) Soluções inovadoras podem-se conseguir "amplificando" os recursos existentes subutilizados, o relevante esta em colocar ao individuo de novo no cenário, tendo principal atenção por grupos em situação de vulnerabilidade (idosos, grávidas, minorias economicamente desfavorecidas, étnica e de gênero, pessoas com enfermidades crônicas, com o vírus da imunodeficiência humana - AIDS - residentes rurais, entre outros) sempre cuidando de manter um ambiente igualitário, equitativo e de inclusão

Pode-se dizer, que o design para a inovação social faz de seus autores uma parte ativa dentro do desenvolvimento de soluções das necessidades do entorno específico onde está inserido. Essas soluções são geradas a partir do estudo focado do ambiente, da observação e eliminação de vieses vindos das interpretações próprias dos futuros beneficiários, mas que podem ser replicadas em outros lugares (a solução, não o produto final).

\section{O Design de serviços}

O design de serviços é uma nova abordagem multidisciplinar que esta em constate evolução, portanto, uma definição sólida ainda é difícil de encontrar. Básicamente o sistema produto-serviço (Product -Services System "PSS") pode se definir como aquela estratégia adotada por algumas empresas para oferecer serviços de qualidade em cenários alternativos de uso de seus próprios produtos, em vez de comprá-los. (BEUREN , GOMES e CAUCHICK, 2013)

Por outro lado, o design de serviços esta focado na criação de experiências planejadas cuidadosamente, que ao ser aplicadas em setores como o de transporte, as comunicações, a saúde, os bancos entre outros, pode oferecer satisfação aos usuários e benefícios importantes a nosso planeta.

Na prática do design de serviços Marc Stickdorn e Jakob Schneider falam de um design de sistemas e processos com um olhar mais holístico e tendo como objetivo o usuário. Surgem cinco princípios fundamentais para abordar: (Stickdorn e Schneider, 2014)

- Centrado no usuário: Os serviços devem ser testados através do olhar do cliente.

- Cocriativo: Todos os stakeholders (partes interessadas 
ou intervenientes) devem ser incluídos no processo de design de serviços.

- Sequencial: o serviço deve ser visualizado como uma sequência de ações inter-relacionadas

- Evidente: Serviços intangíveis devem ser visualizados como artefatos físicos.

- Holístico: Todo o ambiente de um serviço deve ser levado em consideração.

Um design de serviços quebra o paradigma do produto centralizado num bem fisco e valoriza o sistema de comunicação. Sob esta perspectiva, o papel do designer pula a projeção de valores estético-formais, funcionais e de serventia de um produto somente, projetando também a forma na qual os usuários vão se relacionar entre eles e com os produtos (Manizini y Vezzoli, 2002). Quer dizer que o ato de projetar um serviço abrange não só as ferramentas necessárias para satisfazer a atividade e os futuros usuários, também projeta como vão se desenvolver as relações entre as pessoas e os produtos dentro de um sistema.

\subsection{Estudo de caso}

O presente artigo tem como foco de estudo um fenômeno apresentado na Colômbia no que se poderia tomar como uma inovação social, uma vez que partiu da comunidade e se instituiu na cultura. Pode-se entender como um estudo de caso, já que procura entender o por quê da situação, não requer controle sobre os eventos de comportamento e, se trata de um evento contemporâneo. (YIN, 2010)

Para a sua análise, o caso toma como base o design para a sustentabilidade e de serviços, assim como a inovação social. Os "minuteros" apresentam um caso de des- materialização do produto e reaproveitamento de tecnologias obsoletas, e o mais interessante, a oportunidade de conexões inusitadas entre pessoas que normalmente não convergiriam no seu dia-dia.

\subsubsection{Contexto}

Soluções de serviços com tecnologia que muda cada vez mais rápido, em panoramas alternativos de comunicação como redes sociais, plataformas para bater papo ou e-mail ao instante, são oferecidas como recursos de evolução e inovação. Estes conseguem "conectar" às pessoas sem importar sua localização o distancia. Sem desmerecer o que a tecnologia consegui com seus avances, é crucial considerar o alcance destas soluções no contexto mundial real, onde se tem população em condições de pobreza e indigência. Pessoas que eventualmente precisam de comunicação e não tem os recursos para possuir tecnologia própria e entrar na onda da evolução atual.

Este estudo de caso quer trazer a realidade da América Latina e pontualmente a Colômbia como contexto local. A Comissão económica para América Latina y o Caribe (CEPAL) fala no repositório anual "panorama social de América Latina 2014" que a taxa de pobreza em 2013 foi de $28,1 \%$ da população, em quanto à indigência ou pobreza extrema chega ao $11,7 \%$. Isto é, 165 milhões de pessoas se encontram em situação de pobreza, dos quais 69 milhões

Na colômbia o Departamento Administrativo Nacional de Estadística (DANE) revela no boletim de pobreza monetária e multidimensional 2002 - 2014 uma clara diminuição para este período chegando a seu nível mais baixo com um índice de pobreza nacional de $28,5 \%$, dos quais

Figura 1 - América Latina, evolução da pobreza e da indigência, 1980-2014 em porcentagem.

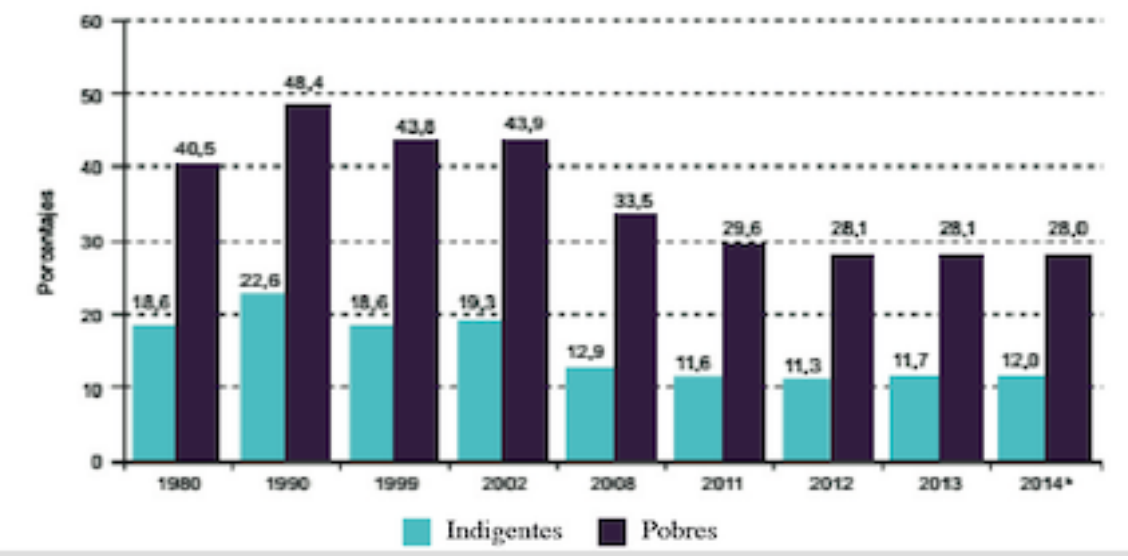

Fonte: Comisión Económica para América Latina y el Caribe (CEPAL), 


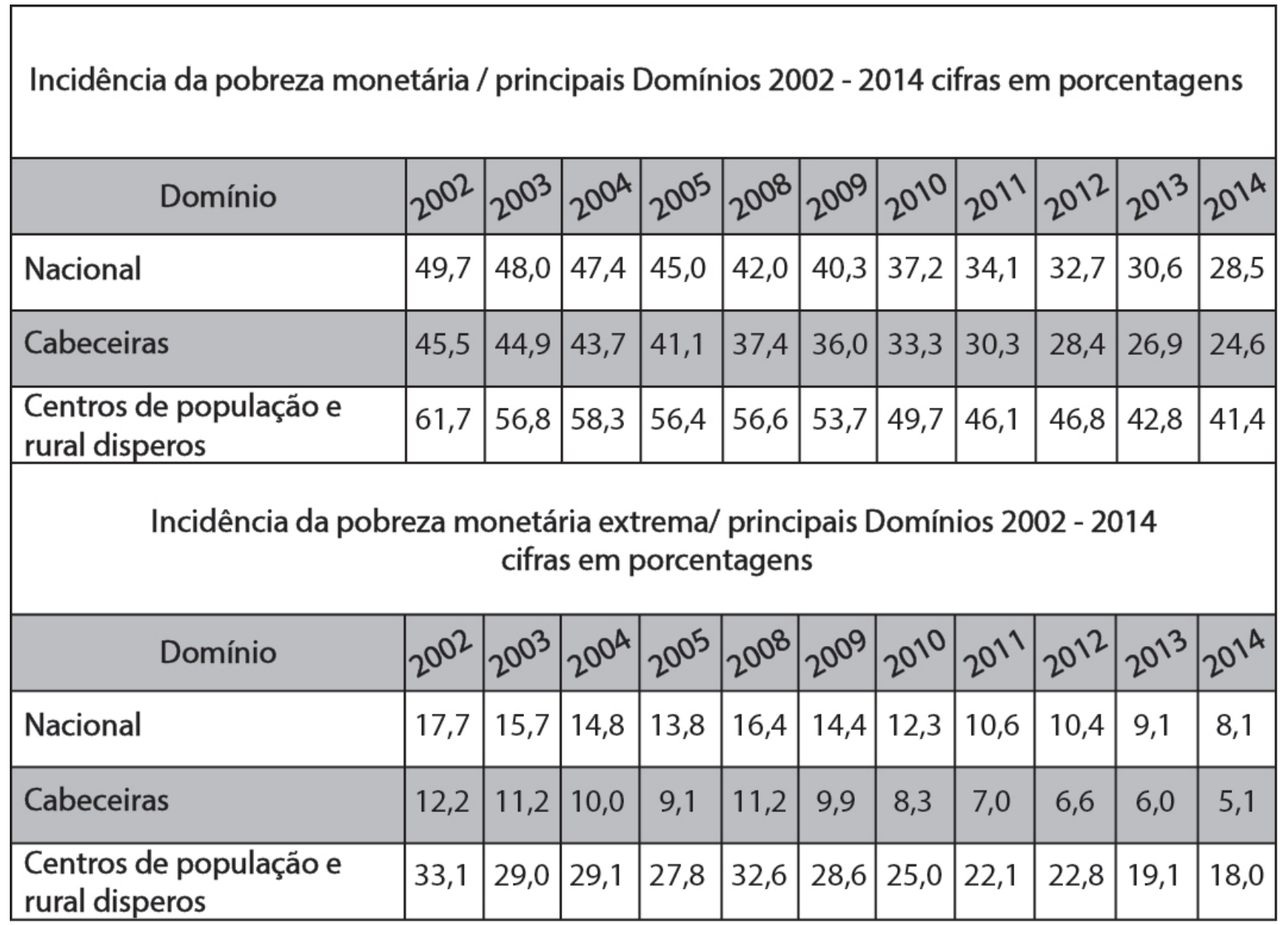

8,1\% estão em pobreza extrema. ver quadro 1.

O Banco Interamericano de Desarrollo (BID) opina que Colômbia, a pesar de ter um bom desempenho, ainda enfrenta problemas de estrutura que limitam o desenvolvimento social e econômico. Especialmente em temas de mobilidade, escasso acesso a serviços financeiros formais e uma baja propensão à inovação em produtos e processos. Além dos esforços as taxas de pobreza se encontrar relativamente altas e persistentes, com limitantes para acessar a educação de qualidade, serviços de saúde e sistemas de proteção social que estimulem a formalidade institucional (BANCO INTERAMERICANO DE DESARROLLO, 2012)

\subsubsection{Localidade}

Quem não tem precisado um minuto para ligar a um celular porque esqueceu recarregar o telefone? Esqueceu seu telefone em casa? Às vezes é preciso ligar para uma pessoa que se encontra numa operadora de telefonia celular diferente e, portanto, o minuto é mais caro, ou, mesmo tendo um plano sai mais barato você ligar desde um "minutero" do que ligar desde seu telefone.

$\mathrm{Na}$ Colômbia existem diferentes operadoras de serviço de telefonia celular que oferecem planos com vantagens para ligações entre números do mesmo operador, planos para ligações entre amigos ou pessoas elegidas entre as quais o valor do minuto sai mais barato, mas, mesmo assim só quando alguma pessoa tiver um plano corporativo com grande quantidade de minutos é quando faz diferença e o minuto custa muito mais barato.

\subsubsection{Ideia do serviço na cidade}

Em todas as cidades de Colombia é possível encontrar os minuteros. Eles se encontram praticamente em qualquer lugar: praças, parques, ruas, esquinas, padarias, mercearias, papelarias, saídas de hospitais, aeroportos, shoppings, etc. Os minuteros são identificados com seus coletes ou jalecos, que por sua vez, fazem às vezes de "propaganda" dos serviços que oferecem e dos valores do 
minuto para cada operadora, como se mostra na figura 2. Este serviço está imerso dentro da cultura colombiana, concorrendo ainda com os aplicativos de ligações gratuitas como Whatsapp, Line, Viber, etc. Já que consegue atender a necessidade de uma ligação imediata e de qualidade, sem depender de redes de wi-fi livres ou planos de dados. Incluso, é preferido por idosos, já que contam com uma "assistência" na hora da marcação, ou por aquelas pessoas com dificuldades de administrar o tempo gasto em ligações, ou do dinheiro que isto representaria se tivessem que pagar uma conta no final do mês.

Básicamente o serviço funciona da seguinte forma:

1. Se aproximar de um minutero;

2. pedir o minuto especificando a operadora local;

3. marcação;

4. finalização da ligação;

5. verificação do tempo da ligação pelo minutero;

6. pagamento do valor da ligação. à igreja e ligar para a família que mora na cidade, entre outras atividades. Ver figura 3.

\subsection{Função}

Este modelo de negócio se configura como inovação social desde o ponto de vista da interação que é criada entre diferentes pessoas nos diferentes contextos onde os minuteros se encontram; num bairro muitos vizinhos se encontram no "ponto de venda" e se conhecem dessa forma, de igual forma com a pessoa que oferece o serviço. Os minuteros são um serviço que pode ser utilizado eventualmente por pessoas de tudo nível social em qualquer lugar de uma cidade ou povo. É um serviço rentável e muito útil e, que já está inserido dentro da comunidade e nos costumes dos colombianos.

O objetivo principal da venda de minutos a celular e telefones fixos consiste na necessidade de pes-

Figura 2 - Minuteros de rua, na cidade - Colômbia.
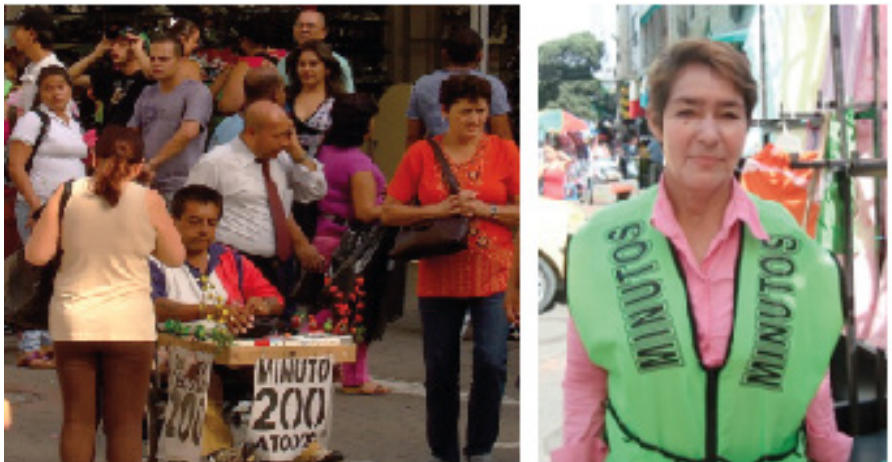

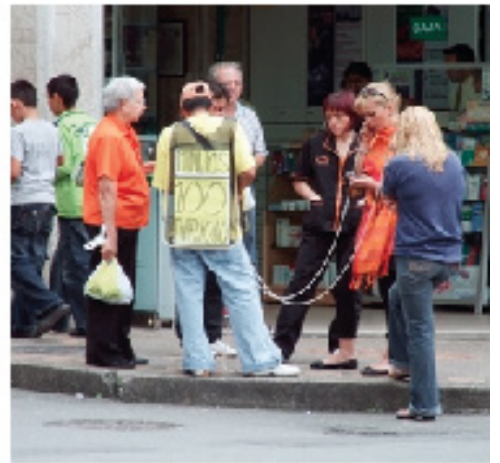

Fonte: Elaborado pelo autor, com base na pesquisa realizada

\subsubsection{Ideia do serviço no ambiente rural}

Em pequenas comunidades rurais entre a geografia Colombiana, também é comum encontrar o serviço de ligação para as diferentes operadoras de telefonia celular ou fixa. Nesta localidades é mais frequente topar o serviço em pequenos negócios como papelarias, padarias, mercearias ou simplesmente no quintal das casas. Neste caso o morador adquire um plano amplo de minutos para oferecer o serviço a seus vizinhos, que muitas vezes moram afastados do centro do povo, e pela mesma localização de suas vivendas não conseguem uma ligação de boa qualidade. Este tipo de pessoas camponesas tem o costume de descer uma vez por semana ao centro do distrito para comprar provisões de comida, limpeza, , assistir soas com dificuldades de arranjar um trabalho ou de aumentar seus ingressos para a manutenção própria ou do núcleo familiar terem uma fonte de dinheiro digna. Embora seja um trabalho desgastante, a venda de minutos é muito popular e oferece uma renda comparável com o salário mínimo legal do país. Aliás da forma de atingir a necessidade que se observou de muitas pessoas fazer ligações a um preço mais barato.

Os minuteros podem "alugar" os chips de celular com diferentes planos corporativos e quantidade de minutos, ou também podem fazer a compra direta do chip. Em qualquer modalidade os ingressos mensais de um vendedor de minutos atingem aproximadamente o valor de 750 reais e o valor do minuto na rua pode custar entre 10 
e 20 centavos de real, e às vezes em promoção pode custar 5 centavos de real.

Os atores principais ao intervir no serviço são: Fornecedores de chips ou aluguéis de chips; vendedores de minutos ou "minuteros"; a publicidade para venda de minutos tais como coletes, camisas, cartazes se encontram com facilidade no mercado e os usuários são pessoas de qualquer nível social, bairro, comunidade, como se pode observar na figura 4. sárias para aumentar o tempo de vida útil do aparelho, no entanto, o serviço principal dos minuteros consiste na "telefonia celular" o que incorre na desmaterialização do celular e se foca no serviço.

\subsection{Impacto na sociedade}

Os casos anteriormente expostos são uma mostra só das iniciativas de design de serviços, inovação social,

Figura 3 - Minuteros ambiente Urbano - Colombia.

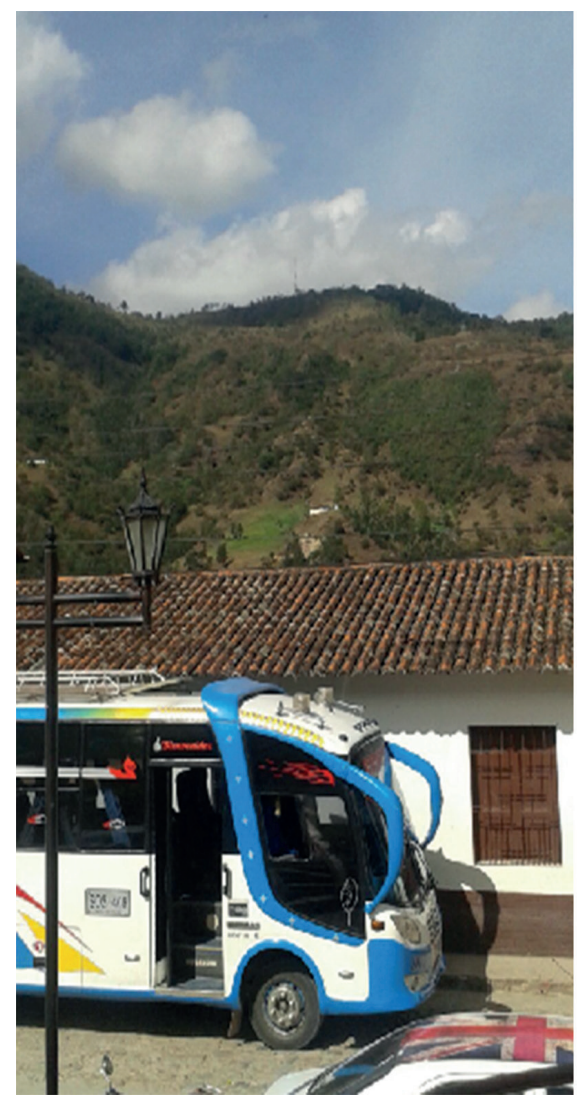

É importante fazer ênfase na questão legal da venda de minutos, que segundo a Constituição Colombiana não é ilegal porque existe um buraco que favorece o exercício e a autocriação de um negócio de forma livre que permita o crescimento da renda de uma pessoa ou a melhoria da sua qualidade de vida.

\subsection{Benefícios / desmaterialização do produto}

Além de oferecer preços competitivos no Mercado, os minuteros também utilizam comumente aparelhos de celular velhos, de gama baixa tipo Nokia 1100 (ver figura 5), que são concertados as vezes que sejam neces- e desmaterialização do produto que estão se levando na Colômbia. Além de ser um modelo de negocio que gera renta e qualidade de vida para os minuteros e suas familias, é um serviço versátil que ajuda à grande parte de população Colombiana a economizar, em especial aquela população de mais baixos recursos. Como falam Manzini e Vezzoli, é uma nova oferta - Um mix integrado de novos produtos/serviços: (MANZINI e VEZZOLI, 2002, P271).

Vamos imaginar um cenário, dentro da transição da chamada "nova economia", que seja caraterizado pela passagem de um sistema centralizado na oferta e consumo de produtos de forma individual, para um outro cenário onde esta oferta se configure como 
uma oferta de um mix de produtos/serviços geridos por terceiros e destinados ao uso coletivo.

A população Colombiana já tem entre seu cotidiano a utilização do serviço de minutos nas ruas, bairros e povos. Isto ressalta como os hábitos são respostas diante de diferentes circunstancias que se repetem, marcando o comportamento do ser humano, que finalmente terminam se executando de forma mecânica. Segundo Dewey, (...) por um aparente paradoxo, o aumento na formação dos hábitos significa o aumento na susceptibilidade e na sensibilidade. Dessa maneira, mesmo que tomemos hábitos como diversos sulcos, o poder de adquirir vários e variados sulcos denota alta sensibilidade (...). desse modo, um velho hábito, uma trilha fixa se desejarmos exagerar, colocasse no caminho do processo de formação de um novo hábito ao mesmo tempo em que a tendência de formação de um novo corta o caminho de um velho hábito (BEZERRA e ORTEGA, 2007)

Então, através desta solução que procura aumentar ao consumo de serviços mais que a obtenção de produtos, inconscientemente se satisfazem diferentes necessidades de uma comunidade. Se faz uma mudança radical nos hábitos dos cidadãos, permitindo a formação de novos com um valor agregado, a fim de obter uma mudança de fundo no comportamento da sociedade e conseguir novas formas de viver.

Figura 4 - Modelo de interação.

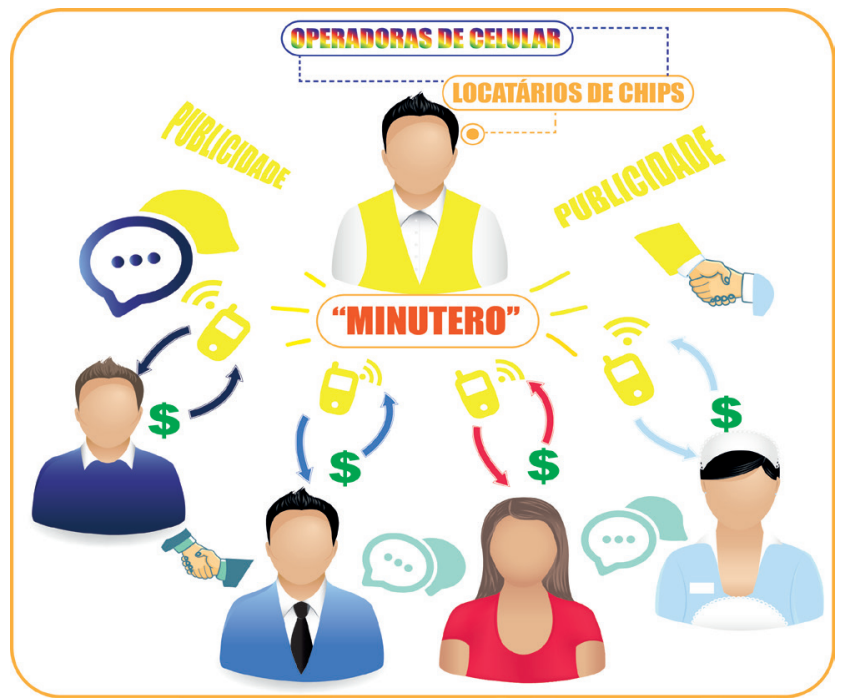

Fonte: Elaborado pelo autor, com base na pesquisa realizada
Figura 5 - Celulares de gama baixa.

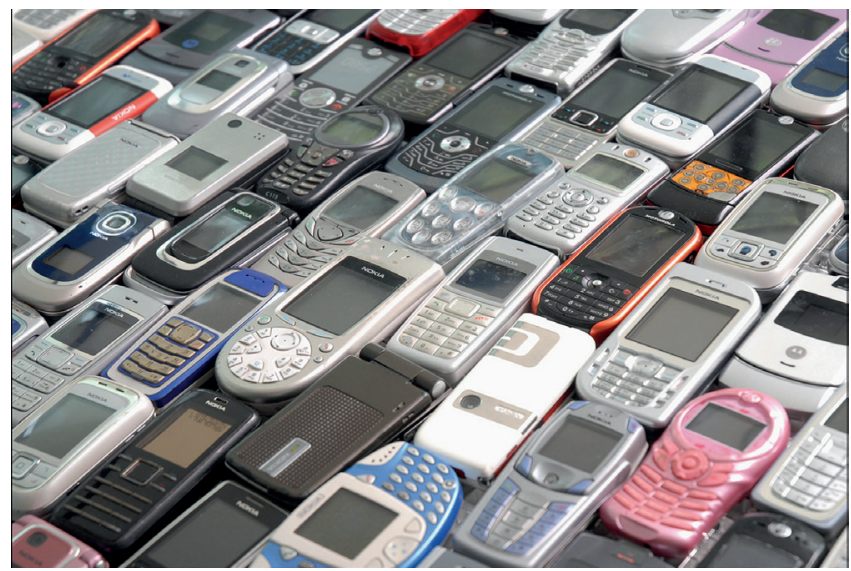

Fonte: Elaborado pelo autor, com base na pesquisa realizada

\section{CONCLUÇÃO}

Mesmo não tendo estadísticas sobre as respostas por parte da cidadania sobre estas novas práticas, o fato dela aproximar-se e participar das iniciativas e o crescente aumento de vendedores nas ruas, bairros e comunidades é uma amostra da receptividade das pessoas para encontrar novas oportunidades em questões já existentes.

Este tipo de soluções têm demonstrado sucesso, não tanto pela questão de serem sustentáveis com o médio ambiente, mas porque envolvem interações diretas entre os atores, de tal forma que todos ganham e que de alguma forma estão baseados na confiança e reputação.

A venda de minutos é um modelo de serviço que pode ser adaptado a outros contextos na América Latina, que compartem os mesmos dilemas frente à comunicação. Aqui demonstra-se como as inovações sustentáveis para a sociedade, podem surgir de ideias simples, bem planejadas e reutilizando tecnologia já existente.

\section{REFERÊNCIAS}

1. BEUREN, Fernanda. H.; GOMES, F. Marcelo. G.; CAUCHICK, Miguel. P. A. Product-service systems: a literature review on integrated products and services. Journal of Cleaner Production, v. 47, p. 222-231, may 2013.

2. BEZERRA, Benilton. J.; ORTEGA, Francisco. Winnicott e seus interlocutores. Rio de Janeiro: EDIOURO Publicações, 2007.

3. BANCO INTERAMERICANO DE DESARROLLO -BID. COLOMBIA: Estrategia de País del BID 2012- 2014: 
1. 2012 Disponível na internet por http em: http://idbdocs. iadb.org/wsdocs/getdocument.aspx?docnum=36643812. Acesso em 20 de agosto de 2015.

2. CHAPMAN, Jonathan. Emotionally Durable Design Objects, Experiences and Empathy. London: Earthscan, 2009. $211 \mathrm{p}$.

3. COMISIÓN ECONÓMICA PARA AMÉRICA LATINA Y EL CARIBE (CEPAL), Panorama Social de América Latina, 2014, (LC/G.2635-P), Santiago de Chile: 2014. Disponível na internet em: http://repositorio.cepal.otg/handle/11362/37626. Acesso em 20 de agosto de 2015.

4. DEPARTAMENTO ADMINISTRATIVO NACIONAL DE ESTADÍSTICA: Pobreza Monetaria y Multidimensional /anexos : 2014. Disponível na internet por http em:

5. http://www.dane.gov.co/index.php/esp/estadisticas-sociales/pobreza/160-uncategorised/6020-pobreza-monetaria-y-multidimensional-2014. Acesso em 20 de agosto de 2015.

6. MANZINI, Ezio. Strategic Design for Sustainability: Towards a New Mix of Products and Services. Environmentally Concius Design and Inverse Manufacturing, 1999. Proceedings. EcoDesign '99: First International Symposium On. [S.I.]: [s.n.]. 1999. p. 434-437.

7. MANZINI, Ezio; VEZZOLI, Carlo. O desenvolvimento de produtos sustentáveis os requisitos ambientais dos produtos industriais. Tradução de Astrid De Carvalho. São Paulo: EDUSP, 2002. 366 p.

8. LANGENBACH, Marcos. Além do apenas funcional. Inovação social e design de serviços na realidade brasileira. 2008. 123f. Dissertação (Mestrado em Engenharia de Produção) - Universidade Federal do Rio de Janeiro, Rio de Janeiro, 2008.

9. PAPANEK, Victor. Arquitectura e design: Ecologia e ética. Lisboa: 70, 2007. 284 p.

10. PAPANEK, Victor. Diseñar para el mundo real: ecologia humana y cambio social. Tradução de Luis Cortes de Alvaro. Madrid: H. Blume, 1977. 339 p.

11. SPARKE, Penny. Diseño y cultura una introducción des- de 1900 hasta la actualidad. Barcelona: Gustavo Gili, 2010.

12. STICKDORN, Marc.; SCHNEIDER, Jacob. Isto é design thinking de serviços. Tradução de Mariana Bandarra. Porto Alegre: Bookman, 2014.

13. THACKARA, John. Plano B: o design e as alternativas viáveis em um mundo complexo. Tradução de Cristina Yamagami. São Paulo: Virgília:Saraiva, 2008. 299 p.

14. YIN, Robert. K. Estudo de caso: planejamento e métodos. Tradução de Ana Thorell. 4. ed. Porto Alegre: Bookman, 2010. $248 \mathrm{p}$. 